\title{
La denominación de origen protegida "Los Pedroches” como ruta gastronómica del jamón ibérico: análisis del perfil del visitante y evolución futura
}

Mạ Genoveva Millán Vázquez de la Torre*

Luis Amador**

Juan Manuel Arjona Fuentes***

Recibido: 2015-12-03 Aprobado: 2016-03-23 Disponible en línea: 2016-06-15

doi:I0.III44/Javeriana.cdri3-77.dopp

Cómo citar este artículo: Millán Vázquez de la Torre, M. G., Amador, L. y Arjona Fuentes, J. M. (2016). La denominación de origen protegida "Los Pedroches" como ruta gastronómica del jamón ibérico: análisis del perfil del visitante y evolución futura. Cuadernos de Desarrollo Rural, I3(77), 63-91. http://dx.doi.org/10.III44/Javeriana. cdri3-77.dopp

* Profesora titular de la Universidad de Córdoba (España), doctora en Ciencias Económicas y

Empresariales, Facultad de Ciencias Económicas y Empresariales, Universidad Loyola. Andalucía (España).

Correo electrónico: gmillan@etea.com

http://orcid.org/0000-0002-6635-4456

** Doctor en Economía por la Universidad de Córdoba, licenciado en Ciencias Económica y Empresariales (sección Empresariales) por la Universidad Pontificia de Comillas, profesor de la Facultad de Ciencias

Económicas y Empresariales, Universidad Loyola, Andalucía (España).

Correo electrónico: lamador@uloyola.es

http://orcid.org/0000-0002-242I-6557

*** Doctor en Ciencias Económicas y Empresariales por la Universidad de Córdoba, profesor en la Facultad de Ciencias Económicas y Empresariales (ETEA) adscrita a la Universidad de Córdoba y en la Facultad de Ciencias Económicas y Empresariales de la Universidad Loyola, Andalucía (España). Correo electrónico: jmarjona@uloyola.es

http://orcid.org/0000-0002-9694-3358

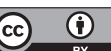




\title{
Resumen
}

Las denominaciones de origen tienen una larga historia en España y el caso del jamón no es una excepción. La denominación de origen protegida del jamón ibérico "Los Pedroches" constituye un ejemplo de simbiosis entre esta figura y la de las rutas gastronómicas. En este trabajo se ha realizado un análisis del perfil del visitante de la comarca en la que esta denominación se asienta, con el objetivo de recabar información que sirva para promover la mencionada denominación como ruta gastronómica y, de esta manera, incrementar las fuentes de ingresos y los niveles de renta y empleo de la población local, potenciando asimismo la multifuncionalidad del territorio rural de la zona.

\section{Palabras clave:}

turismo gastronómico; ruta gastronómica; jamón ibérico; denominación de origen protegida

\section{The Protected Designation of Origin “Los Pedroches” as a Culinary Route for Iberian Ham: Analysis of the Visitor Profile and Future Evolution}

\begin{abstract}
Designations of origin have a long history in Spain, and in the case of ham they are not the exception. The protected designation of origin of the Iberian ham "Los Pedroches" is an example the symbiosis between this figure and that of culinary routes. In this work we carried out an analysis of the profile of visitors of the region where this designation is located, aiming to collect information which can be useful in the promotion of said designation as a culinary route. The purpose is to increase the sources of revenue and the income and employment levels for the local population while also boosting the multifunctionality of the rural territory of the region.
\end{abstract}

Keywords:

culinary tourism; culinary route; Iberian ham; protected designation of origin 


\section{Introducción}

La gastronomía no solo forma parte de la cultura de una sociedad, tendente a satisfacer una necesidad primaria que es la alimentación. Cada día se observa con mayor frecuencia cómo se usan los productos con calidad diferencial, que ostentan algún tipo de sello de origen como parte de la estrategia para comercializarlos en el sector turístico. Esta estrategia procura combinar un proceso de identificación territorial con la creación de marcas o identificaciones con las que el territorio se promociona, tanto en el ámbito interno como en el externo (Cabus, 200ı; Ray, 200I; Cabus y Vanhaverbeke, 2003; Ward et al., 2005).

La demanda creciente de productos con calidad ligada al origen, por parte de consumidores que desean conocer, entre otros, productos alimentarios originarios de un lugar, su producción, cata y forma y procesos de elaboración, ha propiciado propuestas que se relacionan con el turismo gastronómico. En esta estrategia de diferenciación del producto se desarrollan acciones que hacen que los productos se orienten hacia segmentos de consumo importantes y selectivos dentro del mundo del turismo. Para algunos consumidores se dan unas circunstancias que, ligadas a las condiciones naturales e históricas relacionadas con la producción de ciertos alimentos, logran que estos sean reconocidos por su especial calidad, lo que da lugar a que en el mercado su valoración sea superior a la de otros productos del mismo tipo o gama, pero que carecen de tal singularidad.

En la medida en que los ingresos de la población se incrementan, los consumidores tienden a demandar un conjunto más amplio de productos, y podrían empezar a prestar menor atención a la cantidad que a la calidad (Ramos y Garrido, 20I4a). Algunos trabajos han analizado el proceso por el que ciertos segmentos del mercado identifican la calidad diferencial de algunos productos, que a su vez es el punto de partida para un proceso de fortalecimiento de las especificidades territoriales (Fonte, 2008; Vandecandelaere et al., 2010).

En sintonía con las recientes tendencias en la demanda de los consumidores a escala global, en bastantes países se observa un importante giro en las estrategias productivas de los agricultores hacia la diferenciación de sus productos, con base en criterios de calidad. Puede decirse que las producciones especializadas, vinculadas a las especificidades territoriales, constituyen cada vez más una fuente de ventajas competitivas rurales (Ray, I998; Ramos y Garrido, 20I4b) y representan un instrumento importante para el desarrollo rural, capaz de crear un lazo social entre los consumidores y los territorios rurales (Renard, 1999). Pacciani et al. (200I) exploran las diferentes estrategias que se pueden poner en marcha para la valorización de los 
productos típicos en un territorio, en función de los actores involucrados y del rol que desempeñe el territorio. Los agentes vinculados a la cadena de valor del producto acuerdan las condiciones para aprovechar colectivamente la reputación de este, ya sea por medio de estrategias en las que el sello de origen es usado para favorecer exclusivamente a los agentes relacionados con la cadena de valor del producto, o en sentido más amplio, donde el producto con sello de origen actúa como leitmotiv articulado a canastas de bienes, constituyendo las denominadas estrategias territoriales ampliadas, según plantean Pacciani et al. (citados por Aranda, 2015).

Los sellos de origen actúan como monopolios de exclusión, basados en la localización y los límites geográficos, las materias primas y/o a los códigos de prácticas sobre los que se funda la reputación del producto. Estos elementos son los que soportan la calidad diferencial, que es garantizada por el cumplimiento de acuerdos y normas por parte de los productores que usan el sello, de acuerdo con los requisitos registrados en los pliegos de condiciones (Valceschini, citado por Aranda, Gómez y Ramos, 20I4). Las estrategias territoriales que usan los sellos de origen como herramientas articuladas a la promoción del desarrollo de los territorios rurales, muestran diferentes grados de participación y cooperación entre los actores que pertenecen a la cadena agroalimentaria (Aranda, Gómez y Ramos, 20I4).

Por otra parte, según Garrido y Ramos (2013), los procesos de desarrollo rural territorial de la Unión Europea persiguen lograr transformaciones productivas e institucionales en el ámbito local, teniendo en cuenta dos aspectos diferentes: por un lado, el cada vez más marcado carácter dual de la agricultura y el medio rural, consecuencia de la progresiva desregulación de la Política Agraria Común (PAC), y por otro lado, las estrategias de diferenciación de la calidad, como respuesta a las amenazas derivadas de los mercados competitivos. Considerando estos dos aspectos, en los últimos años han surgido diferentes estrategias, entre ellas las denominadas marcas de calidad territorial, que están dando lugar a diferentes experiencias de interés, basadas en una fuerte ligazón entre el signo y el proceso de desarrollo rural del territorio en el que se implantan. La territorialidad, o conjunto de relaciones que existen en un territorio, es el resultado del proceso de construcción social que se basa en esos activos que no se encuentran en ningún otro lugar. En consecuencia, dichos activos constituyen la esencia de las especificidades que puede aprovechar estratégicamente cada territorio para diferenciar sus productos en los mercados.

La denominación de productos agroalimentarios con el nombre de su lugar de producción ha servido tradicionalmente como elemento diferenciador de la calidad de la industria agroalimentaria. En este sentido, diversos territorios rurales en Europa vienen 
tratando de valorizar sus especificidades mediante la creación de signos y sistemas de aseguramiento de la calidad, ya que estas estrategias presentan una marcada capacidad potencial para añadir valor a los sistemas productivos locales (Comisión Europea, 2000; Marescotti, 2003; Becker y Staus, 2008). En el sector agroalimentario existen diferentes sistemas puestos a punto con este objetivo, que han dado como resultado que los sistemas basados en la relación con el territorio de origen sean los que tienen mayor importancia. Según Sanz y Macías (2005) y Rodríguez (2010), los productos con designaciones geográficas de calidad llevan asociados valores de especificidad o tipicidad y excelencia, de diferentes tipos, que constituyen un argumento de primer orden para el desarrollo rural territorial. Por otra parte, estos productos responden a los nuevos gustos de los consumidores, que pueden estar dispuestos a pagar precios más altos por productos que tengan incluidos valores territoriales específicos (Vandecandelare et al., 20I0).

Desde el año 1992, la Unión Europea, con la publicación de diferentes reglamentos, ha iniciado una política de protección y regulación de la diferenciación de sus productos agropecuarios. Así, se reconocen como sellos que garantizan la calidad asociada al territorio y a la identidad territorial, los sellos de indicaciones geográficas protegidas (IGP) y los sellos de denominaciones de origen protegida (DOP) (Allaire et al., 20II). Estos sellos de calidad ligados al territorio, a los que se denomina de primera generación, ofrecen a los consumidores un plus frente a la calidad sin mención de origen o calidad estándar, que resulta obligatoria a partir de las normativas técnico-sanitarias de transformación de productos agroalimentarios y de buenas prácticas agrarias (Garrido, 2014).

Según Ramos y Garrido (20I4b), con los años, y de manera paralela a la implantación de estos signos oficiales, han ido apareciendo también otras marcas no oficiales que también hacen referencia a atributos relacionados con el origen territorial del producto. Suele tratarse de marcas comunes, de uso no individual, registradas bajo la figura legal de marcas colectivas o marcas de garantía, con lo que, de cara al consumidor, ello conlleva de semejanza respecto a los signos oficiales de DOP e IGP. Esta proliferación de marcas territoriales, oficiales o no, de muy diversa naturaleza y con diferente grado de implantación e impacto territorial, junto a la multitud de marcas comerciales y de otro tipo, ha dado lugar a una situación que los autores denominan el laberinto de labels, que puede implicar la banalización del signo y, por tanto, la pérdida de eficacia diferenciadora, con la consecuente desaparición de la renta de especificidad (Garrido, 20I4).

La profusa aparición de marcas de primera generación, además de la proliferación de diferentes tipos de sellos y marcas de origen, paralelos a los distintivos oficiales (Aranda, Gómez y Ramos, 20I4), ha determinado que no siempre se transmitan al consumidor, con la fuerza necesaria, los elementos intangibles que puedan contener los productos que 
amparan. Por tales motivos, han surgido las marcas de segunda generación, ${ }^{1}$ que pretenden capturar valor añadido, gracias a los atributos tangibles e intangibles de los productos del territorio, y que suelen actuar como marcas paraguas que acogen productos de diferentes sectores. Entre estas marcas de segunda generación merecen especial atención las que se han diseñado como estrategias de desarrollo rural territorial: las marcas de calidad territorial. El objetivo de tales marcas es la visualización de su estrategia mediante un signo capaz de ofrecer a los consumidores, internos y externos al territorio, garantías de calidad (de elementos tangibles e intangibles) de diferentes bienes, servicios, elementos patrimoniales (naturales y culturales) e institucionales de un mismo territorio rural (Garrido y Ramos, 2013). Así, los alimentos regionales se conciben como una forma de capital cultural que permite alcanzar un mayor beneficio social y económico en los espacios rurales (Tregear et al., 2007).

Para el desarrollo rural, los productos agroalimentarios con calidad ligada al origen son un recurso de gran importancia. Por medio de actividades de turismo rural estos productos pueden vincularse a las conocidas como estrategias territoriales ampliadas. Este sería el caso de la Ruta Gastronómica del Jamón Ibérico ligada a la denominación de origen protegida "Los Pedroches” (Andalucía, España).

En esta investigación se ha realizado un análisis del perfil socioeconómico del turista ${ }^{2}$ quien, como consumidor, visita la comarca en la que se localiza la producción del jamón ibérico de la mencionada Dop. Además, se ha procedido a estimar un modelo que prediga el número de turistas que visitarán esa zona en el año 20ı6, pudiendo así analizar su tendencia. Con ello se pretende obtener información que pueda ayudar a proponer iniciativas que potencien, en ese territorio, la consolidación de la ruta gastronómica.

\section{Los sellos de calidad diferenciada para los productos agrarios y alimentarios en la Union Europea \\ En el mercado existe una gran riqueza y variedad de productos, pero cuando un producto adquiere cierta reputación, se puede encontrar con usurpaciones e imitaciones. Esta competencia desleal no solo desalienta a los productores, sino que}

\footnotetext{
I Efectivamente, han sido varios los territorios europeos que han lanzado una segunda generación de marcas, construyendo una marca territorial que, a su vez, se integra en otra de ámbito superior o de tercera generación, dentro del Proyecto Marca de Calidad Territorial Europea (MCтE). Para más detalle al respecto, consúltese Ramos y Garrido (20I4b).

2 Centrados en el caso del turista rural, no son muchos los trabajos que se han realizado desde la perspectiva de la demanda. Algunos de los más recientes, relacionados con el turismo rural en España, son los de Albaladejo y Díaz (2003), March y Yagüe (2004), Molera y Albaladejo (2007) y Millán y Melián (2010).
} 
también engaña a los consumidores. Por ello existen unos regímenes de calidad conocidos como DOP, IGP y ETG (especialidad tradicional garantizada) para proteger los productos agrícolas y alimenticios (Ministerio de Agricultura, Alimentación y Medio Ambiente, 2013).

La política europea de calidad reconoce y protege las denominaciones de determinados productos específicos que están relacionados con un territorio o con un método de producción (European Commission, 2006). Este reconocimiento se traduce en los logotipos de calidad que permiten identificar los productos de calidad diferenciada en la UE y que, mediante controles específicos, garantizan además su autenticidad. Dos de ellos tienen connotación geográfica (DOP e IGP). El uso de este tipo de sellos de origen, para diferenciar y hacer expresa en el mercado la calidad que se atribuye al producto por el vínculo territorial, ha venido adquiriendo importancia creciente en las últimas décadas (Aranda, 20I5). El tercero se relaciona con métodos de producción tradicionales (ETG).

El Reglamento de la UE no. 1151/20123 (Unión Europea, 2012), sobre protección de las indicaciones geográficas y de las denominaciones de origen de los productos agrícolas y alimenticios, establece las definiciones de DOP e IGP. Estos son los dos mecanismos de protección que se aplican a los productos agrícolas y alimenticios con calidad ligada, fundamentalmente, al origen del producto. En el mencionado reglamento se define una DOP como un nombre que identifica un producto:

* Originario de un lugar determinado, una región o, excepcionalmente, un país,

* Cuya calidad o características se deben fundamental o exclusivamente a un medio geográfico particular, con los factores naturales y humanos inherentes a él, y

* Cuyas fases de producción tengan lugar en su totalidad en la zona geográfica definida.

Ejemplos de esta categoría serían el aceite de Baena, el jamón de Huelva o el vino de Montilla-Moriles.

Por su parte, una IGP se define como un nombre que identifica un producto:

* Originario de un lugar determinado, una región o un país,

* Que posea una cualidad determinada, una reputación u otra característica que pueda esencialmente atribuirse a su origen geográfico, y

* De cuyas fases de producción, una al menos tenga lugar en la zona geográfica definida.

3 Este reglamento derogaba los reglamentos (CE) №. 509/2006 y (CE) no. 510/2006, que a su vez derogaban los reglamentos (CEE) no. 2082/92 y (CEE) №. 208I/92, respectivamente. 
Ejemplos de esta otra categoría serían el ternasco de Aragón, la alcachofa de Tudela o la ternera gallega.

En el mencionado Reglamento (UE) II5I/20I2 $2^{4}$ también se establece que se podrán registrar como ETG los nombres que describan un producto o alimento específico que:

* Sea el resultado de un método de producción, transformación o composición que correspondan a la práctica tradicional aplicable a ese producto o alimento, o

* Esté producido con materias primas o ingredientes que sean utilizados tradicionalmente.

Para que se admita el registro como ETG de un nombre, este deberá:

* Haberse utilizado tradicionalmente para referirse al producto específico, o

* Identificar el carácter tradicional o específico del producto.

Dentro de la canasta de productos amparados por DoP e IGP en España, y considerando la distribución de su valor económico total (967,83 millones de euros, estimado para el año 20I3), por tipo de producto, los quesos (22,17\% del valor económico total) y los productos cárnicos (22,15\% del valor económico total) son los que aportan mayor valor; los jamones ocupan el tercer lugar (II,89\% del valor económico total) (figura I).

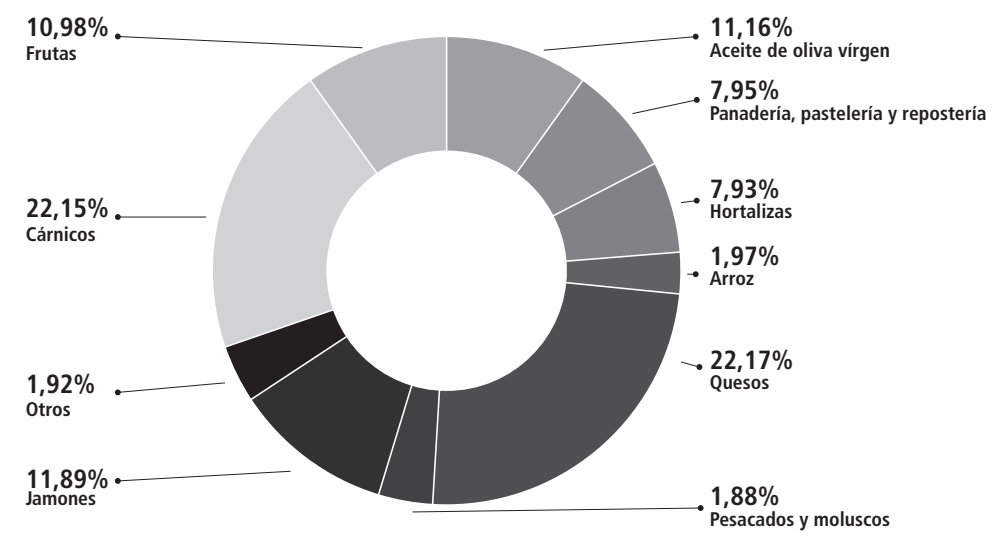

Figura 1. Productos amparados por Dop e IGP. Distribución del valor económico por tipo de producto. Año 2013

Fuente: Ministerio de Agricultura, Alimentación y Medio Ambiente (2014)

4 Otras disposiciones comunitarias de aplicación a las ETG de los productos agrícolas y alimenticios son el Reglamento Delegado (UE) no. 664/20I4, 2014 y el Reglamento de ejecución (UE) no. 668/20I4, 2014. 


\section{Las denominaciones de origen protegidas en productos de España: el caso del jamón}

En España, el cerdo es un animal que se aprovecha tanto en la industria de carnes frescas como en la de carnes preparadas. Dentro de esta última destacan productos como el salchichón, el lomo, el chorizo, etc., siendo el producto estrella el jamón, del cual se pueden identificar algunas variedades. Las más conocidas son el jamón ibérico y el jamón serrano.

Para poder catalogar a los jamones como jamón ibérico, estos han de proceder del cerdo ibérico, el cual debe estar criado en la dehesa, ecosistema singular en el que los componentes fundamentales de la alimentación de estos animales son las bellotas, las hierbas y los rastrojos, que inciden en que se cree la grasa entreverada característica de los productos ibéricos. Esta grasa se infiltra en los músculos del animal, dotando a su carne de una textura peculiar, sabor y untuosidad propios del jamón ibérico. Dentro de la variedad de jamones ibéricos se distinguen a su vez el jamón ibérico de cebo, el jamón ibérico de cebo campo, el jamón ibérico de recebo y el jamón ibérico de bellota.

Por su parte, el jamón serrano (denominado también jamón blanco), que procede de una variedad de cerdo blanco, suele ser más "dulce” que el ibérico, por el escaso grado de salazón que se precisa para que los procesos de secado y maduración se desarrollen adecuadamente. En buena parte, ello se debe a que se cura en clima de sierra, frío y seco (vientos provenientes de las altas cumbres de Sierra Nevada o que soplan en la provincia de Teruel). De acuerdo con el proceso desarrollado para su curación se distinguen, a su vez, tres calidades de jamón serrano: el jamón de bodega, el jamón de reserva y el jamón gran reserva.

En España, actualmente se reconocen cuatro DOP para el cerdo ibérico (figura 2):

* Jamón de Huelva. Elaborado en la sierra de Huelva, en los pueblos de Aracena, Cortegana, Cumbres Mayores, Jabugo, etc.

* Los Pedroches. Comprende las dehesas arboladas de 32 municipios de la comarca de Los Pedroches, al norte de la provincia de Córdoba.

* Jamón de Guijuelo. Se cría en las estribaciones de las sierras de Gredos y de Béjar.

* Dehesa de Extremadura. Se sitúa en las dehesas de alcornoques y encinas de las provincias de Cáceres y de Badajoz.

Una DOP para el jamón serrano:

* Jamón de Teruel. Todas las comarcas de la provincia de Teruel están amparadas para la producción de cerdos y la elaboración de jamones con Dop.

Y dos IGP para el jamón serrano: 
* Jamón de Trevélez. El ámbito de producción de los cerdos protegidos por esta IGP abarca el área geográfica de toda Andalucía; sin embargo, las actividades de elaboración y maduración de jamones y paletas se limitan a nueve municipios de la comarca de la Alpujarra Alta, en la provincia de Granada.

* Jamón de Serón, cuya zona de producción abarca el Valle de Almanzara y Serón, en la provincia de Almería. Se trata de una zona con una climatología suave, inviernos fríos y secos, veranos de temperatura moderada, que favorecen la curación del jamón.

Desde el punto de vista económico, y centrando la atención sobre los datos de comercialización del año 2013 (figura 3), el liderazgo lo detenta la DoP “Guijuelo”, con el 39,74\% de la producción total de jamones, y con el 76,31 \% de la producción total de paletas (cuarto delantero del cerdo). Por su parte, en Andalucía se comercializa el $26,57 \%$ del total de jamones y el I9,24\% del total de paletas. En el caso de la Dop "Los Pedroches”, la producción propia de jamones y paletas, si se la compara con las cifras totales (858 or5 jamones y 313608 paletas), representa una cuota de mercado bastante reducida: $2,26 \%$ del total para los jamones y 4,23\% del total para las paletas.

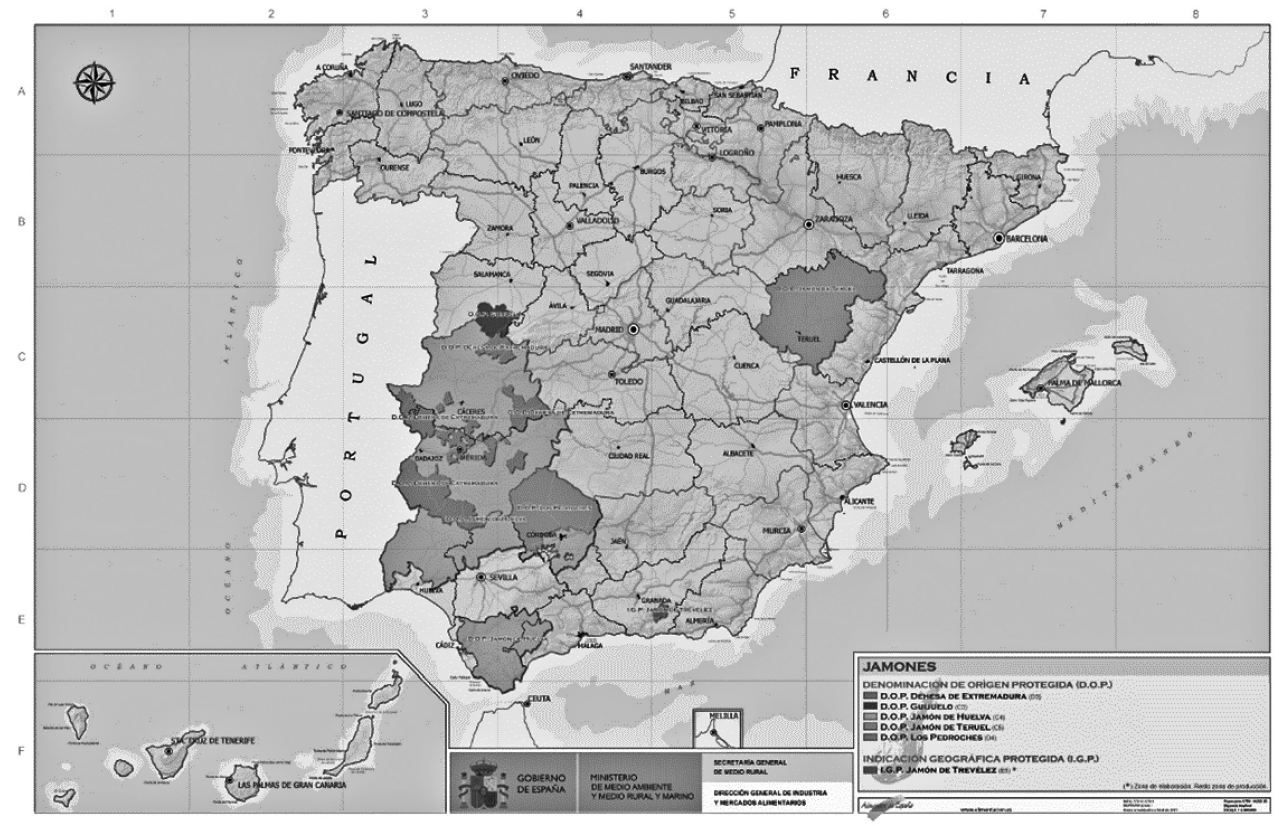

FIgURA 2. Diversificación por tipo de actividad generadora de ingreso a partir del índice de Simpson

Fuente: elaboración propia con datos de la ENHRUM, 2008 
El jamón no solo es un producto gastronómico, sino que, cada día más, se está convirtiendo en un producto turístico. En efecto, en el año 2013, el Ministerio de Agricultura, Alimentación y Medio Ambiente puso en marcha el proyecto "Rutas del Jamón Ibérico: Implantación del club de producto”, con el fin de potenciar el turismo y la creación de empleo en territorios rurales en los que se localiza la producción de jamón (Vereda, 20I3).

Esta iniciativa consiste en una experiencia turística en la que participan los productores vinculados a los Consejos de Reguladores de los productos con Denominación de Origen del Jamón Ibérico (Guijuelo, Los Pedroches, Jamón de Huelva y Dehesa de Extremadura), y quienes localizan su producción en las poblaciones indicadas en los reglamentos de las respectivas Dop. El producto turístico se orienta a que los clientes conozcan el proceso de elaboración del jamón, el entorno paisajístico en el que crían los cerdos y su contexto, ${ }^{5}$ etc.

Este proyecto, de carácter interterritorial, se desarrolla en las cuatro comunidades autónomas que albergan las Dop de jamón (Castilla-León, Andalucía, Aragón y Extremadura). Los objetivos principales del proyecto, dotado con una subvención del Ministerio de 320000 euros, son la creación de empleo, especialmente entre los colectivos más desfavorecidos en el mundo rural: las mujeres y los jóvenes. Además, se hace frente al proceso de despoblamiento de estas zonas y se contribuye a la conservación de la biodiversidad de hábitats de interés comunitario, como son las dehesas de origen ganadero, por medio de la promoción del desarrollo del turismo y de la economía en estas zonas rurales.

Ante el desconocimiento de la efectividad del proyecto, solo la iniciativa privada y el esfuerzo de los Consejos Reguladores de las DoP ofrecen alguna información al respecto. De ahí la necesidad de estudios como el que se propone en esta investigación.

5 En concreto, una oferta turística de estas características podría configurarse de la siguiente manera:

* Alojar a los visitantes en un hotel rural ubicado en la zona que se va a conocer.

* Visitar las localidades más representativas a lo largo de la ruta.

* Visitar y conocer el entorno natural en el que se crían los cerdos; por ejemplo, los paisajes de dehesa.

* Es habitual que, en las zonas de producción, existan centros de interpretación o museos del cerdo ibérico. Por lo tanto, sería interesante realizar una visita a algunas de estas instalaciones.

* Visitar un secadero de jamones, para conocer el proceso de curación del jamón.

* Disfrutar de una experiencia gastronómica en la que estén presentes los diferentes productos del cerdo ibérico y, por supuesto, el jamón como plato estrella.

* Trasladar a los turistas a comercios especializados en la venta de productos del cerdo ibérico. 

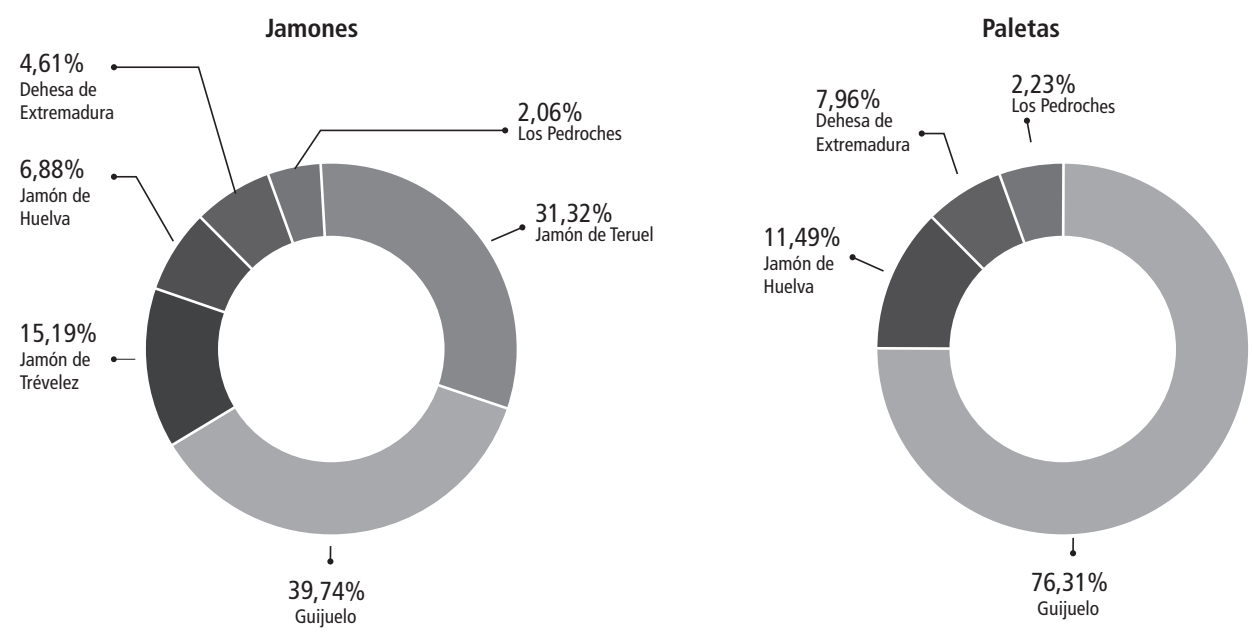

Figura 3. DOP e igP de jamón. Distribución de la comercialización en el año 2013

Fuente: Ministerio de Agricultura, Alimentación y Medio Ambiente (2014)

\section{La relación de las Dop de jamón ibérico y las rutas gastronómicas en España: el caso de la DoP "Los Pedroches”} Los alimentos más típicos de cada zona constituyen un recurso turístico, dado que a su alrededor se conforma un entramado social y una cultura de producción y consumo que son muy atractivas para los visitantes.

Se puede denominar ruta gastronómica a la propuesta turística sustentada sobre la producción de alimentos de una región. Estas rutas representan un itinerario que, de forma organizada, permite reconocer y disfrutar el proceso productivo, la producción primaria del producto agropecuario y la producción agroindustrial y de la cocina regional, considerándolo una expresión más de la identidad cultural. Estas rutas se organizan en torno a un producto clave o, en algunos casos, alrededor de una canasta de productos que las caracterizan y les otorgan identidad; el itinerario se desarrolla sobre la base de la red vial (Schlülter y Thiel, 2008).

Por su parte, las DoP, como sello que hace ostensible la calidad del producto agrario y alimentario, se consideran una de las referencias más prestigiosas para los consumidores. La vinculación entre rutas gastronómicas y DOP es inmediata. Así, los turistas y visitantes, que llegan a las zonas con productos a los que se les otorgan sellos de calidad, los buscan para consumirlos. Por lo tanto, no es de extrañar que algunas de las rutas gastronómicas más afamadas recorran territorios vinculados a Dop. Estas rutas constituyen un instrumento para posicionar los productos y asociarlos a un apelativo de calidad territorial (Barrera y Bringas, 2008; Ramos y Garrido, 20I4b), debiéndose considerar, por tanto, como elementos integrantes de la oferta turística 
de un territorio. En definitiva, la gastronomía forma parte de la identidad cultural del territorio, dado su carácter histórico y cultural. La promoción de determinados alimentos a través de las rutas gastronómicas representa una alternativa para dar a conocer los productos típicos del territorio (Desantes, 2015). La difusión del patrimonio gastronómico y culinario no solo se realiza a través del consumo en el local, sino también a través de la venta de los productos como sonvenir.

En el caso particular del jamón en España, Almodóvar (2010) describe el itinerario de algunas rutas gastronómicas que están vinculadas a diversas Dop (figura 4).

La DOP "Los Pedroches" quedaría vinculada a una ruta que permitiría recorrer parte del espacio geográfico de las provincias de Huelva (Jabugo y Aracena), Sevilla (Cazalla de la Sierra) y Córdoba (Fuente Obejuna, Pozoblanco y Villanueva de Córdoba, entre otros), que se caracteriza por la existencia de amplias dehesas de encinas, alcornoques y quejigos, por las que transitan y se alimentan cerdos de raza ibérica cuyos jamones se secan y curten en secaderos naturales.

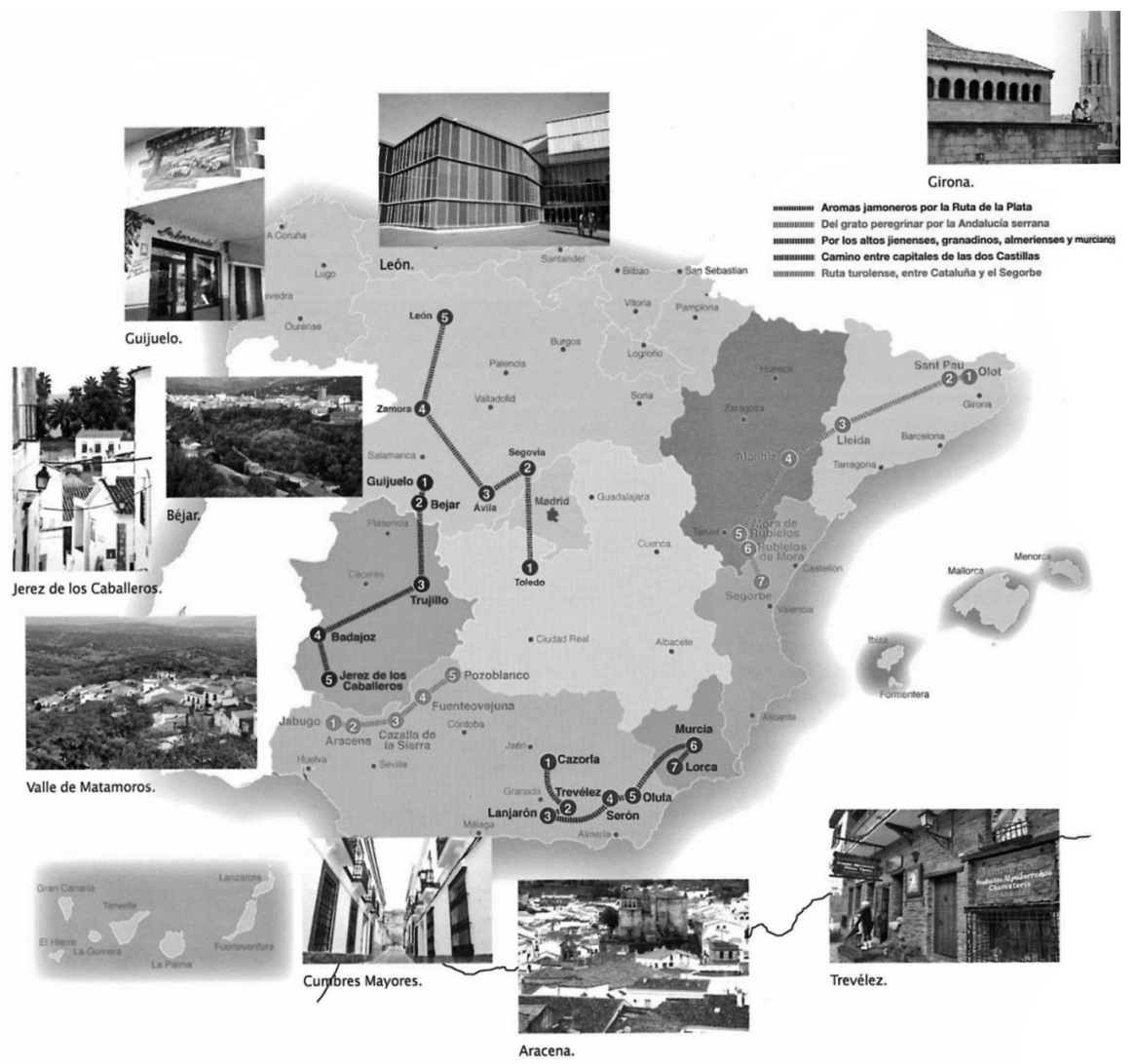

Figura 4. Rutas con sabor de jamones.

Fuente: Almodovar, 2010 


\section{I. La denominación de origen protegida del jamón ibérico "Los Pedroches"}

La DOP “Los Pedroches”, aprobada en el año 1998, ampara la producción de jamones y paletas procedentes de cerdos de raza ibérica. Se encuentra ubicada en el sur de España, en concreto en el norte de la provincia de Córdoba (figura 5), y alberga numerosos pueblos, entre los que destacan Cardeña, Conquista, Fuente Obejuna, Hinojosa del Duque, Pedroche, Pozoblanco, Villanueva de Córdoba, Villanueva del Duque, y las zonas geográficas con cota superior a los trescientos metros de altitud de los términos de Adamuz, Hornachuelos, Montoro, Obejo, Posadas, Villaharta y Villaviciosa. Estas localidades cuentan con amplias zonas de dehesa o de encinares, fuente primordial para la alimentación del cerdo ibérico.

Esta comarca rural cuenta con una población de 57953 habitantes (año 2014), lo que supone el $12,43 \%$ de la población rural de la provincia. Tres pueblos de la zona acumulan el 65\% de la población (Pozoblanco con 17 49r habitantes, PeñarroyaPueblonuevo con il 430 y Villanueva de Córdoba con 9226) (figura 6).

En cuanto al ingreso de la población, Peñarroya-Pueblo Nuevo es el municipio con mayor nivel de renta anual (15 895,87 €) y se encuentra por encima de la renta media de la provincia de Córdoba (I4 532,47 €), aunque muy por debajo de la renta media nacional (22 $780 €$ ) y la europea $(27439 €$ ). Según la actividad económica, el municipio de Pozoblanco es el que concentra el mayor número de oficinas bancarias y establecimientos con actividad económica, siendo por tanto el que presenta una mayor concentración de riqueza y generación de empleo, y considerado el motor de desarrollo de los pueblos de la sierra norte de la provincia de Córdoba.

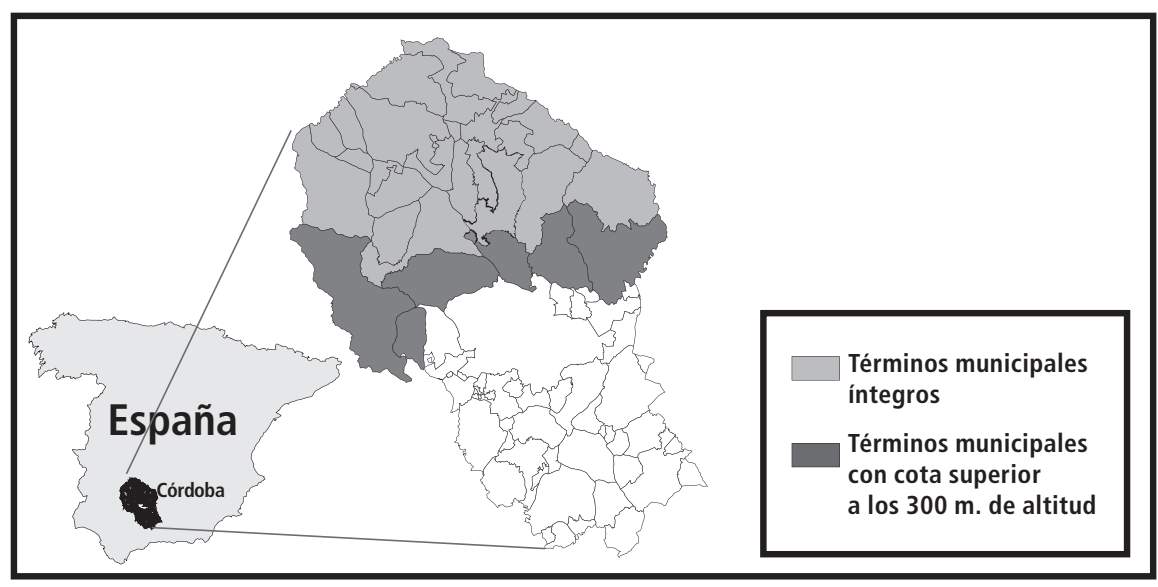

Figura 5. Situación de la Dop del jamón ibérico de "Los Pedroches”. 


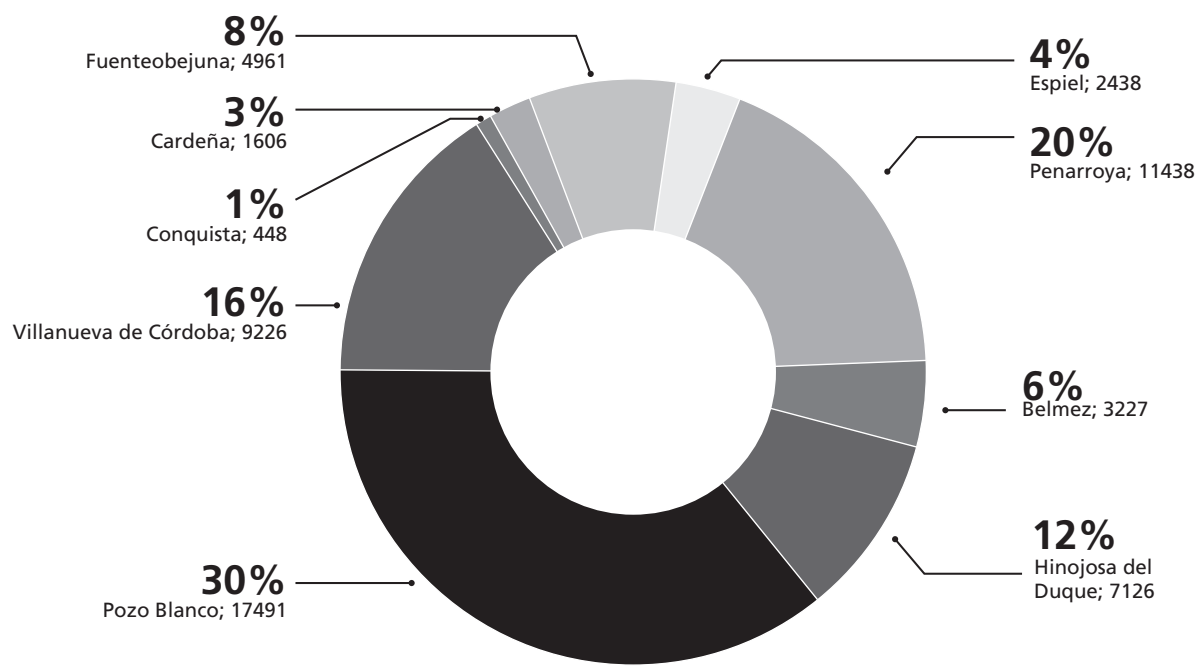

Figura 6. Distribución de los habitantes de los municipios que forman parte la DOP del jamón ibérico de "Los Pedroches". Año 2014

Fuente: elaboración propia a partir de datos obtenidos del Instituto de Estadística de Andalucía (idea) y del Sistema de Información Multiterritorial de Andalucía (sima)

TABLA l. Indicadores económicos de los municipios más importantes que forman parte de la Dor del jamón ibérico de "Los Pedroches"

\begin{tabular}{|c|c|c|c|c|c|c|}
\hline & $\begin{array}{l}\text { RENTA } \\
\text { MEDIA } \\
(€) 2013\end{array}$ & $\begin{array}{c}\text { Estableci- } \\
\text { MIENTOS HO- } \\
\text { TELEROS } 2014\end{array}$ & $\begin{array}{c}\text { ESTABLECIMIENTOS } \\
\text { CON ACTIVIDAD } \\
\text { ECONÓMICA } \\
2014\end{array}$ & $\begin{array}{c}\text { ENTIDADES } \\
\text { DE CRÉDITO } \\
2014\end{array}$ & \multicolumn{2}{|c|}{$\begin{array}{c}\text { Contratos } \\
\text { REgistrados } \\
2014\end{array}$} \\
\hline & & & & & Mujeres & Hombres \\
\hline Espiel & I3 167,95 & 3 & I59 & 2 & 300 & 868 \\
\hline $\begin{array}{l}\text { Peñarroya- } \\
\text { Pueblo Nuevo }\end{array}$ & I5 895,87 & 5 & $70 \mathrm{I}$ & 6 & 976 & I I4I \\
\hline Belmez & 14069,07 & I & $\mathrm{I} 92$ & 2 & 263 & 266 \\
\hline $\begin{array}{l}\text { Fuente } \\
\text { obejunaObejuna }\end{array}$ & IO 269, II & 2 & 308 & 5 & 465 & I 225 \\
\hline $\begin{array}{l}\text { Hinojosa del } \\
\text { Duque }\end{array}$ & 10049,91 & 2 & 526 & 5 & 519 & $93 \mathrm{I}$ \\
\hline Pozoblanco & I3 908,23 & 4 & I 365 & II & 2083 & 4077 \\
\hline $\begin{array}{l}\text { Villanueva de } \\
\text { Córdoba }\end{array}$ & 9875,03 & 3 & 595 & 5 & I 185 & I 824 \\
\hline Conquista & 9254, II & I & 23 & I & 10 & 137 \\
\hline Cardeña & 8740,46 & I & 108 & 2 & 316 & 506 \\
\hline
\end{tabular}

Fuente: elaboración elaboración propia a partir de datos obtenidos del IEA y del sima. 
Solo un municipio tiene una renta superior a la media provincial, en tanto que algunos se encuentran muy por debajo de ese umbral, por ejemplo Cardeña. En este sentido, la promoción y potenciación de esta ruta gastronómica del jamón ibérico DOP "Los Pedroches" podría generar riqueza y, complementada con otras actividades, dinamizar la economía de los municipios de la zona. En el caso particular de Cardeña, su término municipal alberga el Parque Natural Sierra de Cardeña y Montoro, lo cual permitiría combinar el turismo rural que se desarrolla en este parque natural con la ruta de turismo gastronómico.

La DOP “Los Pedroches” tiene adscritas dieciocho industrias, principalmente cárnicas, y está coordinada por un consejo regulador que avala la calidad de los jamones y paletas que estas industrias producen. Los requisitos que se han de cumplir para hacer uso del sello de la DoP involucran acciones tanto de los ganaderos como de los industriales:

A. Ganaderos: producción en la zona geográfica que alberga la Dop, el uso de razas aptas, elementos que prueben que el producto es originario de la zona, procedencia, marcado y control de los animales, sacrificio y despiece, controles analíticos, origen de la alimentación de los cerdos y obtención del producto.

Tabla 2. Datos de producción de la Dop del jamón ibérico de "Los Pedroches"

\begin{tabular}{lcc}
\hline & №. DE CERDOS & PORCENTAJE SOBRE EL TOTAL \\
\hline Bellota & 16 I 44 & 94,74 \\
\hline Recebo & 329 & $\mathrm{I}, 94$ \\
\hline Ibérico de campo & 566 & 3,32 \\
\hline
\end{tabular}

Fuente: Los Pedroches. Denominación de origen, 2015

в. Industriales: localización de la actividad en la zona geográfica, elementos que prueben que el producto es originario de la zona, sacrificio y despiece, proceso de transformación industrial, certificación de las piezas e identificación de productos.

En lo relativo a la producción de dicha DOP (campaña 2013-14), casi toda se concentra en el jamón ibérico de bellota (tabla 2); las otras dos variedades resultan poco relevantes.

\section{Metodología de la investigación}

La investigación se centra en el análisis del perfil del visitante de la zona de la DOP “Los Pedroches", y en la estimación de un modelo Arima (Gujarati y Porter, 2010) 
que prediga el número de turistas que visitarán esa zona en el 20r6. Los datos de la información usada para el análisis de perfil de visitante y la construcción del modelo Arima provienen, respectivamente, de:

1. Información primaria: datos obtenidos a través de un trabajo de campo (tabla 3) sobre los visitantes de la zona.

TABLA 3. Ficha técnica de las encuestas

\begin{tabular}{ll}
\hline Población & Turistas de ambos sexos mayores de i8 años que visitaron las DOP \\
\hline Tamaño muestral & 243 encuestas validas \\
\hline Error muestral & $\pm 4,7 \%$ \\
\hline Nivel de confianza & $95 \% ; \mathrm{p}=\mathrm{q}=0,5$ \\
\hline Sistema de muestreo & Aleatorio simple \\
\hline Fecha trabajo de campo & Octubre del 2013 a noviembre del 2014 \\
\hline
\end{tabular}

Fuente: elaboración propia

Se ha diseñado y distribuido un cuestionario que incorporaba 35 preguntas, las cuales se agrupaban en cinco bloques (perfil sociodemográfico, perfil económico, motivación del viaje, características del viaje y valoraciones y opiniones sobre la ruta gastronómica). Con la encuesta se pretendía obtener información para tipificar el perfil socioeconómico de la demanda turística efectiva.

La población objetivo han sido los turistas que se acercan a la zona, bien a conocer el proceso productivo del jamón ibérico, o bien para asistir a la Feria Comercial del Jamón Ibérico de Bellota de “Los Pedroches” (última edición celebrada en el mes de octubre del 2015 en Villanueva de Córdoba), certamen que es la principal actividad realizada actualmente para la promoción de este producto.

2. Datos recopilados en censos municipales, en la encuesta de población activa y de estadísticas elaboradas con información proveniente del impuesto de actividades económicas para el periodo I999-20I4 (Sistema de Información Multiterritorial de Andalucía, 2015), e información suministrada por la DOP. Para la construcción del modelo Arima se obtuvo información mensual, correspondiente a los últimos ocho años (enero del 2008 a julio del 2015), y sobre el número de turistas que visitaron la DOP de Los Pedroches. Para modelizar la variable demanda de turistas del jamón ibérico en la DOP "Los Pedroches" se utilizó un modelo Arima estacional, donde se estudia la mencionada variable en función de sus valores pasados:

$\Phi(\mathrm{Bs}) \phi(\mathrm{B})(\mathrm{r}-\mathrm{B}) \mathrm{d}(\mathrm{I}-\mathrm{Bs}) \mathrm{D} \mathrm{Y}(\theta \mathrm{t}=\lambda(\mathrm{Bs}) \theta(\mathrm{B})$ at 
TABla 4. Características socioeconómicas de la demanda de turismo gastronómico de la ruta del jamón ibérico de la Dop de "Los Pedroches"

\begin{tabular}{|c|c|c|c|}
\hline Características & Porcentajes & & \\
\hline \multirow{6}{*}{ Personales } & Sexo & $\begin{array}{ll}\text { Mujer } & 49 \% \\
\text { Varón } & 51 \%\end{array}$ & \\
\hline & Edad & $\begin{array}{l}<\mathrm{I} 8 \text { años } \\
\text { I8-30 años } \\
3 \mathrm{I}-45 \text { años } \\
>45 \text { años }\end{array}$ & $\begin{array}{l}4 \% \\
22 \% \\
34 \% \\
40 \% \\
\end{array}$ \\
\hline & Nivel de estudios & $\begin{array}{l}\text { Sin estudios } \\
\text { Estudios medios } \\
\text { Estudios superiores }\end{array}$ & $\begin{array}{l}0,4 \% \\
81 \% \\
18,6 \% \\
\end{array}$ \\
\hline & Estado civil & $\begin{array}{l}\text { Soltero/a } \\
\text { Casado/a } \\
\text { Otros }\end{array}$ & $\begin{array}{l}35 \% \\
44 \% \\
21 \% \\
\end{array}$ \\
\hline & Lugar de procedencia & $\begin{array}{l}\text { Zona rural } \\
\text { Zona urbana }\end{array}$ & $\begin{array}{l}22 \% \\
78 \%\end{array}$ \\
\hline & Nivel de renta & $\begin{array}{l}<\mathrm{I} 000 € \\
I 00 I-I 500 € \\
>\text { I } 500 €\end{array}$ & $\begin{array}{c}33 \% \\
46 \% \\
21 \% \\
\end{array}$ \\
\hline \multirow{3}{*}{ Viaje } & № de días & $\begin{array}{l}<24 \text { horas } \\
\text { Entre dos y tres días } \\
>3 \text { días }\end{array}$ & $\begin{array}{c}91 \% \\
7 \% \\
2 \% \\
\end{array}$ \\
\hline & Gasto medio diario & $\begin{array}{l}<35 € \\
\text { Entre } 36 \text { y } 50 € \\
>50 €\end{array}$ & $\begin{array}{l}3 \% \\
44 \% \\
53 \% \\
\end{array}$ \\
\hline & Personas que le acompañan & $\begin{array}{l}\text { Solo } \\
\text { Familiares } \\
\text { Amigos } \\
\end{array}$ & $\begin{array}{l}3 \% \\
49 \% \\
48 \% \\
\end{array}$ \\
\hline \multirow{3}{*}{ Motivación } & Motivación & $\begin{array}{l}\text { Visitar feria del jamón } \\
\text { Conocer la comarca } \\
\text { Visitar empresas } \\
\text { Otros }\end{array}$ & $\begin{array}{r}75 \% \\
2 \% \\
22 \% \\
1 \% \\
\end{array}$ \\
\hline & $\begin{array}{l}\text { Satisfacción con el } \\
\text { destino }\end{array}$ & $\begin{array}{l}\text { Satisfecho } \\
\text { Indiferente } \\
\text { Insatisfecho }\end{array}$ & $\begin{array}{l}84 \% \\
9 \% \\
7 \% \\
\end{array}$ \\
\hline & $\begin{array}{l}\text { Asistiría a la próxima } \\
\text { feria }\end{array}$ & $\begin{array}{l}\text { Si } \\
\text { No }\end{array}$ & $\begin{array}{l}64 \% \\
36 \%\end{array}$ \\
\hline \multirow{3}{*}{ Motivación } & $\begin{array}{l}\text { Ha visitado otras DOP } \\
\text { del jamón }\end{array}$ & $\begin{array}{l}\text { Sí } \\
\text { No }\end{array}$ & $\begin{array}{l}8 \% \\
92 \%\end{array}$ \\
\hline & $\begin{array}{l}\text { Ha visitado secaderos } \\
\text { de jamón }\end{array}$ & $\begin{array}{l}S i \\
\text { No }\end{array}$ & $\begin{array}{l}54 \% \\
46 \%\end{array}$ \\
\hline & Ha visitado dehesas & $\begin{array}{l}\text { Sí } \\
\text { No }\end{array}$ & $\begin{array}{l}8 \% \\
92 \%\end{array}$ \\
\hline
\end{tabular}




\begin{tabular}{|c|c|c|c|}
\hline Características & Porcentajes & & \\
\hline \multirow{4}{*}{$\begin{array}{l}\text { Conocimiento } \\
\text { gastronómico }\end{array}$} & ¿Es consumidor habitual de jamón? & $\begin{array}{l}\text { Si } \\
\text { No }\end{array}$ & $\begin{array}{l}57 \% \\
43 \%\end{array}$ \\
\hline & $\begin{array}{l}\text { ¿Conoce las distintas } \\
\text { variedades de jamón? }\end{array}$ & $\begin{array}{l}\text { Sí } \\
N_{0}\end{array}$ & $\begin{array}{l}8 \% \\
92 \%\end{array}$ \\
\hline & $\begin{array}{l}\text { ¿Utiliza el jamón en la } \\
\text { elaboración de sus } \\
\text { platos culinarios? }\end{array}$ & $\begin{array}{l}\text { Si } \\
\text { No }\end{array}$ & $\begin{array}{l}52 \% \\
48 \%\end{array}$ \\
\hline & $\begin{array}{l}\text { ¿Valora más si un jamón } \\
\text { es DOP? }\end{array}$ & $\begin{array}{l}\text { Sí } \\
\text { No }\end{array}$ & $\begin{array}{l}87 \% \\
13 \%\end{array}$ \\
\hline
\end{tabular}

Fuente: elaboración propia

\section{Resultados y discusión}

\section{I. Análisis univariante y bivariante del perfil del turista del jamón en la DOP "Los Pedroches"}

De acuerdo con la información obtenida por medio de las encuestas, el perfil socioeconómico del turista del jamón ibérico que visita la DOP "Los Pedroches" es el de un varón, de edad superior a los 45 años, de nivel de renta entre roor y $1500 €$, casado y proveniente de zonas urbanas.

$\mathrm{El} 75 \%$ de los encuestados indicaron que se habían desplazado al lugar para asistir a la Feria Comercial del Jamón Ibérico de Bellota de "Los Pedroches”, y que los medios por los cuales habían tenido noticia de su celebración habían sido la prensa y la radio. Los turistas que visitan la zona con la intención de consumir el jamón ibérico están muy satisfechos con la experiencia vivida (82\%). Ello pone de manifiesto que la oferta que se realiza recibe una alta valoración. Además, el 64\% de los encuestados indicó su intención de volver en ediciones futuras.

Con respecto a las características del viaje para realizar este tipo de turismo, destaca que el 91\% de los encuestados no pernocta en la zona, debido a:

A. La poca infraestructura hotelera existente (pocas plazas). El 89\% de los encuestados la considera deficiente (figura 7).

B. La escasez de oferta complementaria en la zona. Se trataría de actividades relacionadas con la cultura del jamón, como: visitas a dehesas y secaderos de jamón; asistencia a matanzas artesanales, con cerdos ibéricos puros; o a la participación en la elaboración de los tradicionales productos de la matanza. En definitiva, serían actividades para atraer un volumen mínimo de turistas que favorezcan la inversión en infraestructuras, especialmente la hotelera, aumentando el número de pernoctaciones, lo cual favorecería la creación de puestos de trabajo en torno a la restauración y la hostelería. 
Las sinergias con otras rutas más conocidas, como la Dop del aceite de oliva de Montoro-Adamuz, que engloba a pueblos como Espiel y Villanueva de Córdoba, pertenecientes tanto a la DOP del jamón como a la DOP del aceite, podrían promover el desarrollo de actividades conjuntas que contribuyan a satisfacer mejor al cliente, pues ambos productos están valorados con una calidad muy alta por los turistas (Millán y Pérez, 20I4).

Figura 7. Valoración de los servicios turísticos de la ruta del jamón de "Los Pedroches"

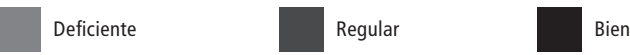

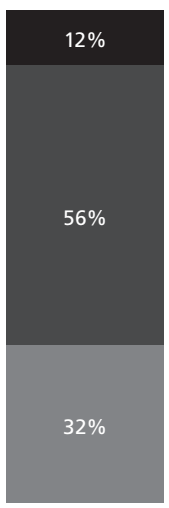

Información y señalización

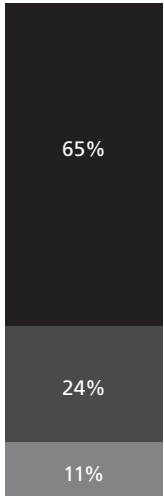

Restauración

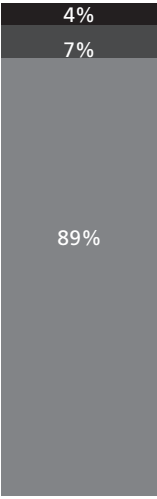

Alojamiento
$15 \%$

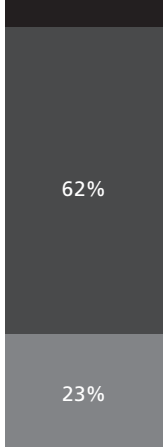

Oferta complementaria

Fuente: elaboración propia

De acuerdo con los resultados del análisis bivariante (tablas de contingencia, estadístico Chi-cuadrado), se evidencia que existe relación entre la satisfacción de los visitantes por la experiencia vivida en esta feria del jamón y su propósito de volver en próximas ediciones. Las personas más satisfechas repetirán visita, lo que podría facilitar la creación de algunos puestos de trabajo más estables $(\varkappa 2=48,6 \mathfrak{z}$, variables relacionadas para $\alpha=0,05)$. También están asociadas las variables lugar de procedencia del turista y motivación de su desplazamiento $(\varkappa 2=123,35$, para $\alpha=0,05)$.

Las personas que proceden del ámbito urbano manifiestan, como motivo principal para desplazarse, el conocimiento de la feria. En este sentido, resultaría conveniente la implementación de algunas estrategias para realizar una oferta combinada, vinculando esta ruta gastronómica del jamón ibérico a algunas otras modalidades 
turísticas que se ofertan en la comarca. En definitiva, se trata de crear sinergias entre la oferta de la ruta gastronómica y el turismo rural, el turismo industrial, el turismo cinegético y el oleoturismo, entre otros. Promocionar la ruta gastronómica, vinculándola a otras ofertas turísticas, permitiría alterar el patrón actual que presentan las visitas a la zona, caracterizado por un alto grado de estacionalidad, además de elevar el número de pernoctaciones y su duración media. Para intentar superar la estacionalidad que presentan las visitas a la zona, vinculadas fuertemente a la celebración de la feria comercial, además de la oferta turística combinada, deberían potenciarse también otros eventos culturales o gastronómicos:

* Las jornadas de la matanza, dado que más de un $76 \%$ de los visitantes provienen de un entorno urbano y, por tanto, desconocen este tipo de actividades y tradiciones.

* La creación de un museo o centro de interpretación del jamón, al igual que ocurre con el Centro de Interpretación del Aguardiente en Cazalla de la Sierra (provincia de Sevilla) o el Centro de Interpretación de la Miel en Andújar (provincia de Jaén). La demanda de un producto turístico, experiencial y participativo, tiene una respuesta ideal en la visita y conocimiento directo de los lugares de producción como lagares, almazaras, viñedos, queserías etc., donde el contacto con el producto y su proceso de elaboración es muy cercano, dándose así una interesante intersegmentación con el turismo industrial. En este sentido, se deberían establecer conciertos con los ganaderos y propietarios de las explotaciones, que se localizan en las dehesas, para que los turistas puedan realizar visitas y conocer cómo se cría el cerdo ibérico en este entorno natural tan singular.

* La organización de cursos de cortadores, de catadores de jamón, de congresos de análisis sensorial, etc., al igual que hace, por ejemplo, la DOP "Priego de Córdoba”. Todo ello atraería a turistas deseosos de aprender, vivir y experimentar nuevas experiencias y sensaciones.

También existe una relación importante entre el gasto medio diario, realizado por los visitantes, y su grado de satisfacción $(\varkappa 2=85,36$, para $\alpha=0,05)$. Las personas más satisfechas con la experiencia vivida en la comarca presentan un gasto medio superior, debido a que han comprado productos de la zona, lo que podría, si se plantea con acierto, reactivar el comercio, especialmente el del jamón.

Por tanto, como ya se ha indicado, muchos de estos turistas están dispuestos a volver a la zona, debido a su alto grado de satisfacción con el resultado obtenido en el primer viaje, lo cual permitiría generar mayor riqueza y crear empleo más estable en el sector de la hostelería, la restauración y también en el del comercio. 


\section{Turistas}

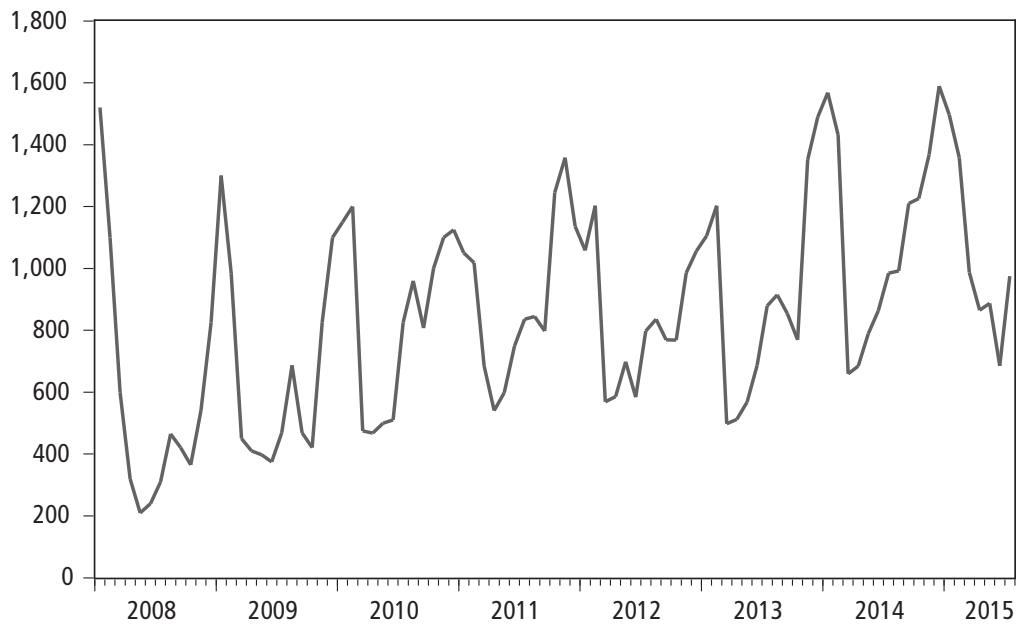

Figura 8. Evolución del número de turistas de la ruta del jamón de "Los Pedroches" (enero del 2008 a julio del 20I5)

Fuente: elaboración propia

\subsection{Modelo de previsión de demanda}

No existen estudios de previsión de demanda de turismo del jamón, de ahí la novedad de este trabajo.

$\mathrm{Al}$ observar la figura 8, la evolución del número de turistas que visitan la DOP "Los Pedroches” (en definitiva, la ruta del jamón ibérico “Los Pedroches"), se puede apreciar que es una variable estacional (los puntos máximos de la gráfica corresponden a los meses de diciembre y enero de cada año) y con tendencia en varianza, la cual se ha corregido con la transformación de Box-Cox $\lambda=0,2$, y tendencia en media y en ciclo que se han corregido con una diferenciación en media y en ciclo.

TABla 5. Modelo Arima de estimación de la demanda de turistas del jamón.

Método Least Squares

Sample (adjusted): 2009M03 2015 Mo7

\begin{tabular}{|c|c|c|c|c|}
\hline VARIABLE & Coefficient & STD. ERROR & T-STATISTIC & РRов. \\
\hline $\operatorname{AR}(\mathrm{I})$ & $-0,371156$ & 0,107260 & $-3,460337$ & 0,0009 \\
\hline MA (2) & $-0,768152$ & 0,073457 & $-10,45716$ & 0,0000 \\
\hline R-squared & 0,288002 & Mean dependent var & & 0,001046 \\
\hline Adjusted R-squared & 0,278508 & S.D. dependent var & & $0,174 \mathrm{II} 3$ \\
\hline S.E. of regression & $0, \mathrm{I} 47892$ & Akaike info criterion & & $-0,959034$ \\
\hline Sum squared resid & I,6404II & Schwarz criterion & & $-0,898156$ \\
\hline Log likelihood & 38,92280 & Hannan-Quinn criter. & & $-0,934683$ \\
\hline Durbin-Watson stat & 1,929587 & & & \\
\hline
\end{tabular}


De acuerdo con los datos disponibles e incorporados al modelo, este ha estimado, de previsión de demanda mensual de turistas del jamón, un Arima (I,I,2) (O,I, $)$ I2:

$\left.(\mathrm{I}+0,37115 \mathrm{~B})(\mathrm{I}-\mathrm{B})_{\mathrm{I}}\left(\mathrm{I}-\mathrm{B}_{12}\right)\right)_{\mathrm{I}}$ Turistaso, $2=\left(\mathrm{I}+0,768 \mathrm{IS}_{5} \mathrm{~B}_{2}\right) \mathrm{at}$

La tabla 5 a contiene las estimaciones del modelo, siendo la columna coefficient la que representa los valores estimados de los coeficientes. La columna probabilidad (prob), al ser esta inferior a 0,05 , indica que los coeficientes son significativos a nivel individual.

Para que el modelo Arima sea válido, de cara a hacer predicciones, los errores deben cumplir determinadas propiedades. Una de ellas es que la varianza sea constante a lo largo del tiempo, siendo el test ARCH el adecuado para comprobarlo. Realizado este test (tabla 5b), al ser la probabilidad del estadístico Chi-Square o,1928, superior a 0,05 , indica que la varianza de los errores es constante (homecedástica), siendo por tanto el modelo válido para calcular estimaciones futuras.

Realizadas las estimaciones de demanda con el modelo, los resultados son los que se muestran en la tabla 6.

TABLA 5a.

Heteroskedasticity Test: ARCH

\begin{tabular}{llll}
\hline F-statistic & $\mathrm{I}, 689342$ & Prob. F( $\mathrm{I}, 74)$ & 0,1977 \\
\hline Obs*R-squared & $\mathrm{I}, 696276$ & Prob. Chi-Square( $\mathrm{I})$ & 0,1928 \\
\hline
\end{tabular}

TABLA 5b.

Heteroskedasticity Test: ARCH

\begin{tabular}{llll}
\hline F-statistic & $\mathrm{I}, 689342$ & Prob. F( $(\mathrm{I}, 74)$ & 0,1977 \\
\hline Obs*R-squared & $\mathrm{I}, 696276$ & Prob. Chi-Square $(\mathrm{I})$ & 0,1928 \\
\hline
\end{tabular}

FuENTE: elaboración propia.

Tabla 6. Previsión de demanda de turismo año 2015

\begin{tabular}{lllc}
\hline Mes & 2015 (DATO REAL) & 2016 (DAto Estimado) & Variación \\
\hline Enero & $\mathrm{I} 497$ & $\mathrm{I} 509$ & $\Delta \circ, 80 \%$ \\
\hline Febrero & $\mathrm{I} 358$ & $\mathrm{I} 390$ & $\Delta 2,35 \%$ \\
\hline Marzo & 987 & $\mathrm{I} 062$ & $\Delta 7,59 \%$ \\
\hline Abril & 865 & 856 & $\nabla_{\mathrm{I}, 04 \%}$ \\
\hline Mayo & 685 & 725 & $\Delta 5,83 \%$ \\
\hline
\end{tabular}

Fuente: elaboración propia 
Se prevé que para el año 20I6, el número de turistas que visitan la DOP crezca con respecto al año anterior, pues de los seis meses estimados ${ }^{6}$ todos presentan un incremento que oscila entre 0,8 y 7,59\%, a excepción del mes de abril, para el que se prevé una caída de ı, $04 \%$, debido en parte a la variación de las fechas de la Semana Santa con respecto a años anteriores.

De acuerdo con lo anterior, se requiere, para atender convenientemente a los turistas, mejorar la infraestructura hotelera y promover otras iniciativas a modo de oferta turística complementaria. En este sentido, las estrategias pueden ser diversas. La dehesa, como entorno natural, y la proximidad del Parque Natural de la Sierra de Cardeña y Montoro permiten desarrollar actividades de senderismo y turismo de naturaleza. La cercanía de la cuenca minera de Peñarroya-Pueblonuevo permite realizar turismo industrial (actividades de la minería). Igualmente, está próxima la comarca aceitera vinculada a la DOP de aceite de oliva de Montoro-Adamuz, donde se pueden desarrollar actividades de oleoturismo. Por último, la cercanía de la capital de la provincia (Córdoba) hace posible la combinación de actividades de turismo religioso, turismo cultural y turismo gastronómico. Todo ello puede contribuir a generar más riqueza en los pueblos de la zona norte de Córdoba.

\section{Conclusiones}

En el contexto actual, caracterizado por la globalización y por una alta estandarización de productos y servicios, cada vez un mayor número de turistas buscan conocer la identidad y la cultura local de los destinos que visitan. En este sentido, el turismo gastronómico puede desempeñar un papel relevante en la transmisión de valores tradicionales, la autenticidad y la identidad de un territorio. De esta forma, se desarrolla un nuevo canal que permite la comercialización de un producto diferenciado, pudiendo a su vez este último actuar como "producto lanza" para el desarrollo de estrategias que promocionen el territorio en su conjunto.

Las visitas a la zona donde se localiza la Dop del jamón ibérico "Los Pedroches" presentan un alto grado de estacionalidad, pero con una demanda creciente. Se trata de una comarca de la Sierra Morena cordobesa que los turistas visitan por diversos motivos: turismo rural, turismo cinegético y, fundamentalmente, para asistir a la Feria Comercial del Jamón Ibérico (celebrada el mes de octubre).

6 Solo se han realizado seis predicciones, pues a medida que aumenta el número de predicciones, al basarse los cálculos del modelo en datos anteriores previstos, su grado de fiabilidad va disminuyendo. 
Hoy en día, las motivaciones del turista son cada vez más variadas y resulta arriesgado vincularlas a segmentos turísticos concretos. Ciertamente, suele haber una motivación central, pero es frecuente que una persona se vea atraída por la visita a monumentos, cuando acude a un congreso, o por la gastronomía autóctona cuando va a esquiar. En el caso del turismo gastronómico de esta comarca, cuyo protagonismo corresponde al jamón ibérico, las sinergias que se pueden desencadenar entre diferentes segmentos turísticos son múltiples, por lo que se presenta una gran oportunidad para aprovechar todos los recursos del territorio y explotar así su potencial turístico completamente.

En general, el turista gastronómico no suele disponer de información ni de propuestas, claras y definidas, que le permitan valorar previamente todas las potencialidades de este tipo de rutas. El caso de la DOP "Los Pedroches" es un ejemplo ilustrativo de ello. Como ruta gastronómica del jamón ibérico, apenas se ha promocionado como tal, a diferencia de lo ocurrido, por ejemplo, con la Ruta del Vino de Montilla-Moriles (Centro Enogastronómico de la Ruta del vino MontillaMoriles), o con las rutas del aceite de oliva de la provincia cordobesa (Baena, Priego de Córdoba, etc.). La consecuencia es que esta Dop, considerada parte de una ruta gastronómica del jamón ibérico, es una gran desconocida para el turista en general. Sin embargo, podría lograrse un incremento sustancial en el flujo de visitantes si se publicitara más y mejor.

Las industrias cárnicas de la zona deberían implicarse más en la promoción de la ruta del jamón ibérico, y no limitarse a exponer sus productos en los stands ubicados en el recinto de la Feria del Jamón Ibérico de Bellota. Dado que lo que se pretende es reducir la estacionalidad de las visitas, debe realizarse una oferta continua al turista gastronómico, y no concentrarla en la feria de octubre, alternativa que imposibilita la creación de un volumen de empleo estable relevante.

Ante la falta de una infraestructura suficiente de alojamientos rurales en la zona, se podría optar por acondicionar algunos cortijos, localizados en la dehesa, como hoteles rurales. De esta manera, el turista podría disfrutar de oferta culinaria de calidad: carnes ibéricas y, por supuesto, el jamón ibérico, complementado con el aprovechamiento de las posibilidades que ofrece la dehesa, como entorno natural, o la cercanía del Parque Natural de la Sierra de Cardeña y Montoro, la comarca minera de Peñarroya-Pueblo Nuevo o de la capital de la provincia.

Muchas regiones y comarcas han empezado a considerar el paisaje un aspecto sobre el cual fundamentar la promoción y la diferenciación de sus productos alimentarios. De este modo, no solo se proyecta la imagen del producto en sí, sino 
también, a través de la estampa evocadora de un determinado paisaje cultural, se promocionan todas las experiencias, vivencias y expectativas ligadas al disfrute de cada producto. El efecto sobre el incremento de visitantes y de la actividad avala la apuesta por el paisaje como identificador cultural del territorio. Sin duda alguna, la imagen que tiene un espacio natural como la dehesa puede representar un aspecto clave, pues un producto/destino sin imagen es un producto/destino que no existe a los ojos del mercado global. La imagen del destino debe asociarse con experiencias sensoriales, con paisajes evocadores y diferenciadores, de ahí la importancia del paisaje como elaboración cultural y rasgo identitario del espacio que se visita.

En términos del aporte al desarrollo rural, el proceso productivo del jamón ibérico contribuye a preservar la dehesa como modelo de desarrollo sostenible. En el caso analizado, los productores acogidos a esta DOP no deberían obviar las nuevas orientaciones de los patrones de consumo de alimentos, dado que cada vez son más los turistas (consumidores) que demandan alimentos ecológicos, cuya producción es respetuosa con el medio ambiente.

El desarrollo del turismo gastronómico, cuyo objeto sea el jamón ibérico de la DOP "Los Pedroches", contribuirá a integrar la función productiva primaria tradicional con la terciaria especializada y, además, permitirá aumentar el gasto medio diario de los visitantes (que ronda los $66 €$ actualmente) e incrementar así las fuentes de ingresos y los niveles de renta y empleo de la población local, potenciando asimismo la multifuncionalidad del territorio rural de la zona.

Por último, la promoción de la Dop "Los Pedroches”, como parte integrante de una ruta gastronómica del jamón ibérico, es una iniciativa que debería contar con el apoyo tanto del ámbito privado como del público. Además, resulta fundamental concienciar a los agentes implicados de que esta alternativa puede contribuir a paliar la crisis en la que se encuentran inmersos los pueblos de la zona norte de la provincia de Córdoba (creación de puestos de trabajo, tanto en el sector de la hostelería como en el del comercio), así como a potenciar las relaciones interculturales entre sus habitantes y los visitantes, lo que generaría un aumento de riqueza en una zona económicamente deprimida.

\section{Referencias}

Albaladejo, I. P. y Díaz, M. T. (2003). Un modelo de elección discreta en la determinación del perfil del turista rural: una aplicación a Murcia. Cuadernos de Turismo, II, 7-19. 
Allaire, G., Casabianca, F. y Thevenod-Mottet, E. (20II). Geographical origin: A complex feature of agro-food products. En E. Barham y B. Sylvander (Eds.), Labels of origin for food: local development, global recognition (pp. I-I2). Oxfordshire, UK: CABI, $20 \mathrm{II}$.

Almodóvar, M. A. (2010). Alimentación en España: Jamones. Distribución y Consumo, II4, I00-I09.

Aranda, Y. V., Gómez, A. C. y Ramos, E. (20I4). Incorporación de dinámicas territoriales en un modelo para la selección de sellos de origen, Revista Española de Estudios Agrosociales y Pesqueros, 237, 13-47.

Aranda, Y. V. (2015). Productos agroalimentarios e identidad del territorio: un modelo de decisión para orientar la selección de sellos de origen (tesis doctoral). Departamento de Economía, Sociología y Política Agrarias, Universidad de Córdoba, España.

Barrera, E. y Bringas, O. (2008). Las rutas alimentarias: una arquitectura turística basada en la identidad de los alimentos. Gastronomic Sciences. Food for Thought, $3(8)$.

Becker, T. y Staus, A. (2008). European food quality policy: the importance of geographical indications, organic certification and food quality insurance schemes in European countries. Presentado al I20 EAAE Congress. Gante, Bélgica, 26-29 de agosto.

Cabus, P. (200I). The meaning of local in a global economy. European Planning Studies, 9(8), IоII-10з8.

Cabus, P. y Vanhaverbeke, W. (2003). Towards a neo-endogenous rural development model for the Flemish countryside. Regional Studies Association International Conference, Pisa Conference Centre, Pisa, Italia, I2-15 de abril del 2003.

Comisión Europea (2000). Protected designations of origin and protected geographical indications in Europe: Regulation or policy? FAIR I-CT: p. 95-0306 Final report.

Consejo Regulador de la DOP “Los Pedroches” (2015). Diferenciación del producto. Normativa.

Desantes, A. (2015). Ruta del Jamón Ibérico Dehesa de Extremadura: Por los caminos gastronómicos extremeños. Origen: la Revista del Sabor Rural, 82, 26-27.

European Commission (2006). European policy for quality agricultural products. Office for Official Publications of the European Communities. Luxemburgo.

Fonte, M. (2008). Knowledge, food and place. A way of producing, a way of knowing. Sociologia Ruralis, 48(3), 200-222.

Garrido, G. y Ramos, E. (20I3). Calidad y desarrollo rural: una propuesta metodológica para la evaluación de marcas de calidad territorial. Revista Española de Estudios Agrosociales y Pesqueros, 234, 127-157.

Garrido, G. (20I4). Las estrategias de desarrollo rural territorial basadas en diferenciación por calidad ligada al origen: el caso Marca Calidad Rural en España (tesis doctoral). 
Departamento de Economía, Sociología y Política Agrarias, Universidad de Córdoba, España.

Gujarati, D. y Porter, D. (2010). Econometría (5a ed.). México: McGraw-Hill.

Instituto de Estadística y Cartografía de Andalucía [IEA] (2015). Recuperado el is de octubre del 2015, de http://Instituto de Estadística y Cartografía de Andalucía.

March, I. y Yagüe, R. M. (2004). Análisis del comportamiento de la demanda de turismo rural desde la experiencia de la comarca El Alto Palencia. Estudios Geográficos, 65(254), I21-I42.

Marescotti, A. (2003). Typical products and rural development: Who benefits from $\mathrm{PDO} / \mathrm{PGI}$ recognition? Presentado al 830 EAAE Seminar. Chania, Grecia, 4-7 de septiembre.

Millán, M. G. y Melián, A. (2010). El turismo rural en el sur de España: Análisis de la oferta y demanda. Cultur, Revista de Cultura e Turismo, 4(2), 69-9I.

Millán, M. G. y Pérez, L. M. (2014). Comparación del perfil de enoturistas y oleoturistas en España. Un estudio de caso. Cuadernos de Desarrollo Rural, II(74), I67-I88.

Ministerio de Agricultura, Alimentación y Medio Ambiente (2013). Preguntas y respuestas frecuentes. Recuperado el 22 de octubre de 2015, de http://www.magrama. gob.es/es/alimentacion/preguntas-frecuentes

Ministerio de Agricultura, Alimentación y Medio Ambiente (2014). Datos de las denominaciones de origen protegidas (D.o.P.) e indicaciones geográficas protegidas (I.G.P.) de productos agroalimentarios. Año 20I3. Secretaría General de Agricultura y Alimentación, Dirección General de la Industria Alimentaria.

Molera, L. y Albaladejo, I. P. (2007). Profiling segments of tourists in rural areas of South-Eastern Spain. Tourism Management, 28(3), 757-767.

Pacciani, A., Belletti, G., Marescotti, A. y Scaramuzzi, S. (2001). The role of typical products in fostering rural development and the effects of regulation (EEC) $2081 / 92$. Presentado al 730 Seminar of the European Association of Agricultural Economists. Ancona, Italia.

Ramos, E. y Garrido, D. (20I4a). Towards a “2nd Generation” of Quality Labels: a Proposal for the Evaluation of Territorial Quality Marks. Cuadernos de Desarrollo Rural, II(74), IOI-I23. Recuperado de http://dx.doi.org/IO.III44/Javeriana.CRDII-74.tsgq Ramos, E. y Garrido, D. (20I4b). Estrategias de desarrollo rural territorial basadas en las especificidades rurales. El caso de la marca Calidad Rural ${ }^{\circledR}$ en España. Revista de Estudios Regionales, I00, I0I-I29.

Ray, C. (1998). Culture, intellectual property and territorial rural development. Sociologia Ruralis, 38(I), 3-20. 
Ray C. (200I). Culture economies: A perspective on local rural development in Europe. Centre for Rural Economy, Dept. of Agricultural Economics and Food Marketing, University of Newcastle upon Tyne.

Renard, M. C. (1999). The interstices of globalization: The example of fair coffee. Sociologia Ruralis, 39(4), 484-500.

Rodríguez, A. (2010). Denominaciones geográficas: más que instrumentos comerciales. Revista Nacional de Administración, I(I), I39-I48. Recuperado de http:// www.uned.ac.cr/rna/articulos/15.pdf

Sanz, J. y Macías, A. (2005). Quality certification, institutions and innovations in local agro-food systems: Protected designation of origin of olive oil in Spain. Journal of Rural Studies, 2I(4), 475-486.

Schlüter, R. G. y Thiel, D. (2008). Gastronomía y turismo en Argentina. Polo gastronómico Tomas Jofré. Pasos Revista de Turismo y Patrimonio Cultural, I6(2), 249-268.

Sistema de Información Multiterritorial de Andalucía [SIMA] (20I5). Recuperado el ıo de octubre de 2015, de http://Instituto de Estadística y Cartografía de Andalucía. Sistema de Información Multiterritorial de Andalucía (sima).

Tregear, A., Arfini, F., Belleti, G. y Marescotti, A. (2007). Regional foods and rural development: The role of product qualification. Journal of Rural Studies, 23, I2-22.

Unión Europea (2012). Reglamento (UE) n. II5I/20I2 del Parlamento Europeo y del Consejo de 2I de noviembre de 2012 sobre los regímenes de calidad de los productos agrícolas y alimenticios. Recuperado de http://eur-lex.europa.eu/LexUriServ/LexUriServ.do?uri=OJ:L:20I2 :343:0001:0029:es:PDF

Valceschini, E. (I999). Les signaux de qualite credibles sur les marches agroalimentaires: certifications officielles et marques. En L.C. Lagrange (Ed.), Signes officiels de qualite et developpment agricole. Actes du colloque sFER, Clermont Ferrand, I4 et I5 avril (pp. I47-I66).

Vandecandelare, E., Arfini, F., Belletti, G. y Marescotti, A. (2010) Linking people, places and products. Roma: FAO - Sinergi.

Vereda, J. (20I3). Las rutas del jamón ibérico. Potencian el turismo rural. Actualidad Gastronómica. Recuperado de http://actualidadgastronomica.es/ rutas-del-jamon-iberico-nuevo-proyecto-de-turismo-gastronomico/

Ward, N., Atterton, J., Kim, T., Lowe, P., Phillipson, J. y Thompson, N. (2005). Universities, the knowledge economy and neo-endogenous rural development. Centre for Rural Economy Discussion. Paper Series no... 